\title{
Aleukemic Leukemia Cutis: Case Report and Review of Literature
}

\begin{abstract}
Aleukemic leukemia cutis (LC) is an extremely rare clinical presentation. All patients eventually develop acute leukemia, mostly monocytic and myelomonocytic types. It is a diagnostic challenge, resolved by careful immunophenotyping and cytochemistry. The diagnosis indicates a poor prognosis. Here, we report a case of an 85-year-old white male with LC, who had normal peripheral blood and bone marrow histology. The fragility of our patient precluded any definite anti-leukemic therapy.
\end{abstract}

Keywords: Acute myeloid leukemia, cytochemistry, histology in leukemia, immunophenotyping, leukemia cutis

\section{Introduction}

As leukemia cutis (LC) is a somewhat rare conditionand has been reported in many leukemic ${ }^{[1]}$ subtypes, the exact incidence is not well characterized. Of the acute myelogenous leukemia developing in patients with human T-lymphotropic virus type 1 (HTLV-1), one of the highest incidences of LC is noted. Acute myelomonocytic leukemia (AML-4) and AML-M5 have the highest rate of cutaneous infiltration of all the FAB subtypes and has been recorded as high as $30-50 \%{ }^{[2-5]}$

In most cases of $\mathrm{LC}$, the patients have a preceding or concurrent diagnosis of systemic disease. In as many as $7 \%$ of patients, LC precedes bone marrow or blood involvement. ${ }^{[6]}$ The prevalence of $2.9 \%-3.7 \%$ of AML cases have been noted to present with LC. This excluded patients with HTLV-induced AML which is much higher in Japan and Caribbean. ${ }^{[7]}$ In general, LC patients have a poor survival. Here, we present a rare case of aleukemic LC (ALC) in an elderly male with negative bone marrow and blood involvement, which posed a diagnostic challenge initially.

\section{Case Report}

An 85-year-old man with past medical history of Alzheimer's early dementia, localized prostate cancer treated with $\mathrm{X}$-ray telescope presented with widespread erythematous rash and cutaneous nodules

This is an open access journal, and articles are distributed under the terms of the Creative Commons Attribution-NonCommercial-ShareAlike 4.0 License, which allows others to remix, tweak, and build upon the work non-commercially, as long as appropriate credit is given and the new creations are licensed under the identical terms.

For reprints contact: reprints@medknow.com in February 2017. The rash first appeared around patient's neck and then involved his trunk and lower extremities over a period of 3 weeks. The patient reported generalized weakness since onset of skin lesions. He denied fever, chills, chest pain, shortness of breath, weight loss, changes in bowel or bladder habits. The patient denied a history of recent travel or change in medications. He was a lifetime nonsmoker, reported minimal alcohol intake. Punch biopsy of one of the abdominal wall lesions was performed. Meanwhile, there was a rapid progression of skin lesions leading to hospitalization. Physical examination was significant for multiple nontender, erythematous, and violaceous lesions and nodules of various sizes involving the neck, upper chest, back, and thighs up to knees bilaterally. Complete blood count revealed mild normocytic anemia with hemoglobin of $12.5 \mathrm{~g} / \mathrm{dl}$, normal white blood cell and platelet counts. Peripheral blood smear revealed slight increase in the percentage of monocytes in peripheral blood (20.1\%) without absolute monocytosis. Chemistry profile revealed minimal transaminitis, mild alkaline phosphatase elevation; normal serum and urine electrophoresis except minimal hypergammaglobulinemia, normal serum lactate dehydrogenase, and kidney function testing. Serum lysozyme level was elevated at $21.1 \mathrm{mg} / \mathrm{ml}$ (normal 5-11). Flow cytometry on skin biopsy was noncontributory because of paucity of cells. Skin biopsy sections revealed diffuse atypical cellular infiltrate in the upper dermis. The epidermis was uninvolved.

\footnotetext{
How to cite this article: Karam D, Agrawal B. Aleukemic leukemia cutis: Case report and review of literature. Indian J Med Paediatr Oncol 2018;39:443-5.
}

\section{Dhauna Karam, Bharat Agrawal}

Department of

Hemato-Oncology, Captain

James A. Lovell Federal Health

Care Centre, Chicago, Illinois,

USA

Address for correspondence:

Dr. Dhauna Karam,

2222, Green Bay Road,

North Chicago, IL 60064,

Illinois, USA.

E-mail: dhauna.karam@

gmail.com

Access this article online

Website: www.ijmpo.org

DOI: 10.4103/ijmpo.ijmpo_75_17

Quick Response Code:

口为岁利回

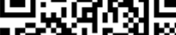

Pring

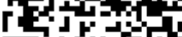

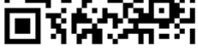


The infiltrate consisted of large cells with large blastic nuclei with folds or a reniform appearance. The cells were positive for CD4, CD43, CD68, and lysozyme. There was weak staining for bcl-6 in many cells, but this did not account for true positivity. There was no significant positivity in the cells of interest for CD2, CD3, CD5, CD7, CD8, CD20, CD79a, PAX6, CD30, ALK-1, CD10, CD163, myeloperoxidase, CD34, CD15, CD56, CD123, CD117, and EBER. The findings were consistent with LC that appeared to show monocytic differentiation. Bone marrow aspiration and biopsy revealed the presence of all hematopoietic cell lines with normal progressive maturation [Figures 1 and 2]. Promonocytes and mature monocytes were slightly increased. Blasts and promonocytes accounted for only $3.6 \%$ or 500 cell count [Figure 3]. Core biopsy showed areas of hypercellularity, normal CD34 count with no increase in blasts. Flow cytometry revealed a minor population of monoclonal normal sized B lymphocytes. There was no evidence of an expanded population of leukocytic blasts or plasma cells. Fragility of our patient precluded any anti-neoplastic therapy.

\section{Discussion}

LC is the invasion of neoplastic leukocytes or their early forms into the different layers of skin or subcutis. ${ }^{[8]}$ The lesions may take different appearances and are highly variable in the presentation. They may look like flesh colored to violaceous papules, nodules, or plaques. ${ }^{[9]}$ Terms such as granulocytic sarcoma, monocytic sarcoma, primary extra medullar leukemia, and chloroma have been used as synonyms for LC. Terms such as myeloid or lymphoid cutis have been used to further characterize the type of leukemia cells. ${ }^{[10]}$

LC usually presents as a manifestation of previously diagnosed acute or chronic leukemias, lymphoid malignancies, myelodysplastic syndromes, or blastic phase of chronic myeloid leukemia. In rare cases, LC may precede the development of systemic disease, then known as ALC. A dermatologist, not uncommonly is involved in aiding the diagnosis. In the latter, a drastic change in chemotherapy regimen will be needed. ${ }^{[11]}$

LC is often associated with many other sites of extensive involvement, and generally a very poor prognosis has been noted. ${ }^{[12-15]}$ The pathophysiology and mechanism leading to migration of leukemic cells to the skin is not well understood. It has been proposed that chemokine integrin and other adhesion cell adhesion molecule 1 molecules may promote homing of $\mathrm{T}$ and $\mathrm{B}$ leukemic cells. Acute leukemia patients with $t(8: 21)$ translocation, expression of CD 56 have been linked to extramedullary disease. ${ }^{[16]}$

In HTLV-1-induced leukemia cases, the rich expression of CCR4, chemokine receptor on the leukemia cell surface could be involved in the tendency of adult T-cell leukemia to involve the skin. In the skin, the ligands

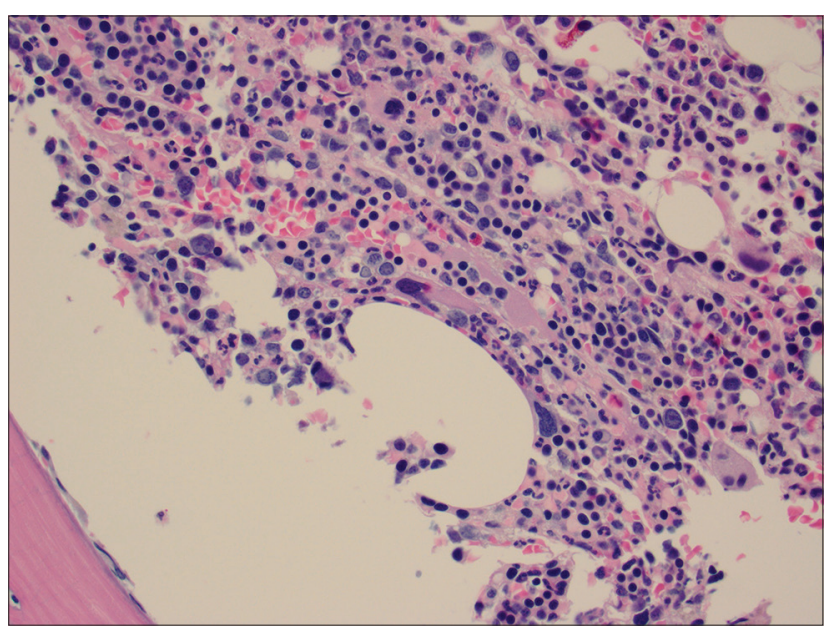

Figure 1: Bone marrow biopsy revealing all cell lines

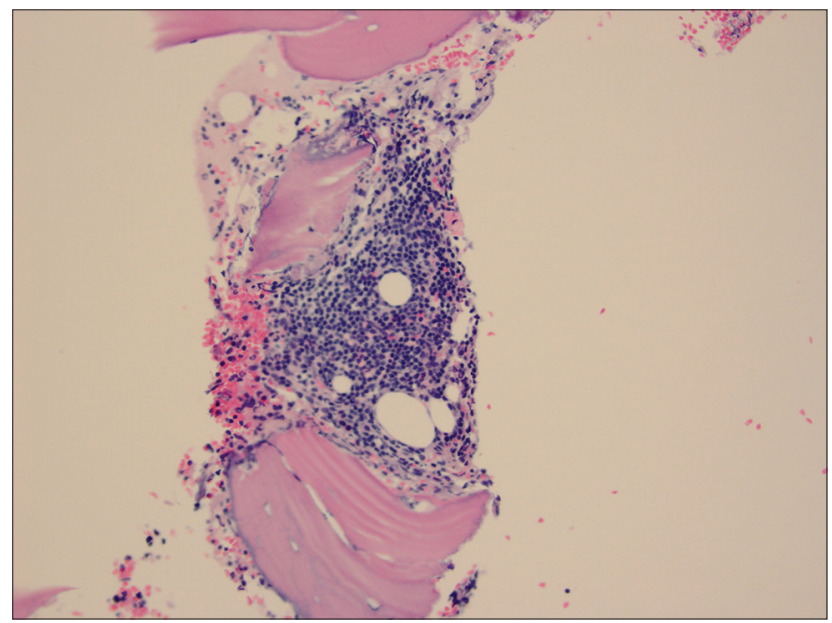

Figure 2: Core biopsy suggested hypercellularity

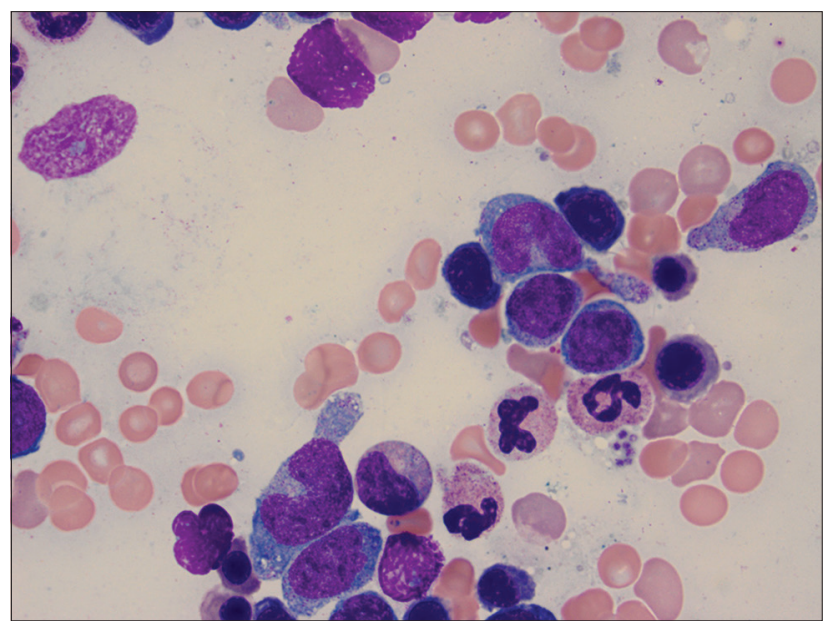

Figure 3: Blasts and promonocytes in bone marrow examination

thymus activation regulated chemokine (TARO/CCL 17) and macrophage involved chemokine (MDC/CCL 22) are present. ${ }^{[17]}$

The factors connected with cutaneous infiltration include aneuploidy of chromosomes, acute myeloid leukemia with 
monocytic differentiation and involvement of other extra medullary sites. In acute monocytic leukemia, there is an expression of $\mathrm{T}$ cell-related antigens on the cell surface. This may induce homing to skin selectively. ${ }^{[18,19]}$

In a study of 18 cases of acute myelomonocytic LC, 14 patients demonstrated cutaneous lymphocytes antigen (CLA) staining. The presence of CLA may provide a predilection of migration to skin in those leukemic cells. A study by Kaddu et al. revealed an average survival term in AML to 7.5 months. ${ }^{[20]}$ Our patient has ALC with monocytic differentiation in the skin. Considering his advanced age and developing dementia, the patient and his family were reluctant to initiate therapy.

\section{Financial support and sponsorship}

Nil.

\section{Conflicts of interest}

There are no conflicts of interest.

\section{References}

1. De Coninck A, De Hou MF, Peters O, Van Camp B, Roseeuw DI. Aleukemic leukemia cutis. An unusual presentation of acute myelomonocytic leukemia. Dermatologica 1986;172:272-5.

2. Vishalakshi V, Torsekar RG, Shinde S. Aleukemic leukemia cutis. Indian J Dermatol Venereol Leprol 2007;73:109.

3. Ohno S, Yokoo T, Ohta M, Yamamoto M, Danno K, Hamato N, et al. Aleukemic leukemia cutis. J Am Acad Dermatol 1990;22 (2 Pt 2):374-7.

4. Yoder FW, Schuen RL. Aleukemic leukemia cutis. Arch Dermatol 1976;112:367-9.

5. Cho-Vega JH, Medeiros LJ, Prieto VG, Vega F. Leukemia cutis. Am J Clin Pathol 2008;129:130-42.

6. Yones SS, Khorasgani MG, Iqbal T, Arrifin N, Mehta R, Skibinska G, et al. Aleukemic leukemia cutis. Egypt Dermatol Online J 2009;5:1-8.

7. Wagner G, Fenchel K, Back W, Schulz A, Sachse MM. Leukemia cutis-epidemiology, clinical presentation, and differential diagnoses. J Dtsch Dermatol Ges 2012;10:27-36.
8. Husak R, Blume-Peytaki U, Orfanos CE. Aleukemic leukemia cutis in an adolescent boy. N Engl J Med 1999;340:893-4.

9. Ratnam KV, Khor CJ, Su WP. Leukemia cutis. Dermatologic Clin 1994;12:419-31.

10. Vitte F, Fabiani B, Bénet C, Dalac S, Balme B, Delattre C, et al. Specific skin lesions in chronic myelomonocytic leukemia: A spectrum of myelomonocytic and dendritic cell proliferations: A study of 42 cases. Am J Surg Pathol 2012;36:1302-16.

11. Gil-Mateo MP, Miquel FJ, Piris MA, Sánchez M, Martin-Aragonés G. Aleukemic "leukemia cutis" of monocytic lineage. J Am Acad Dermatol 1997;36 (5 Pt 2):837-40.

12. Burg G, Schmoeckel C, Braun-Falco O, Wolff HH. Monocytic leukemia. Clinically appearing as 'malignant reticulosis of the skin'. Arch Dermatol 1978;114:418-20.

13. Strayer DS, Phillips GB, Herzig G, Bari W, Santa Cruz DJ. Acute myelomonocytic leukemia presenting as a primary cutaneous lymphoma of true histiocytes. J Am Acad Dermatol 1982;7:229-35.

14. Bain B, Manoharan A, Lampert I, McKenzie C, Catovsky D. Lymphoma-like presentation of acute monocytic leukaemia. J Clin Pathol 1983;36:559-65.

15. Miliauskas JR. Dermal monocytic sarcoma/monoblastic tumour: Report of two cases of acute monocytic leukemia with initial dermal manifestations only. Pathology 1986;18:249-53.

16. Baer MR, Stewart CC, Lawrence D, Arthur DC, Byrd JC, Davey FR, et al. Expression of the neural cell adhesion molecule CD56 is associated with short remission duration and survival in acute myeloid leukemia with $\mathrm{t}(8 ; 21)(\mathrm{q} 22 ; \mathrm{q} 22)$. Blood 1997;90:1643-8.

17. Ishida M, Iwai M, Yoshida K, Kagotani A, Okabe H. Adult T-cell leukemia/lymphoma accompanying follicular mucinosis: A case report with review of the literature. Int J Clin Exp Pathol 2013;6:3014-8.

18. Diaz-Cascajo C, Bloedern-Schlicht N. Cutaneous infiltrates of myelogenous leukemia in association with pre-existing skin diseases. J Cutan Pathol 1998;25:185-6.

19. Cronin DM, George TI, Sundram UN. An updated approach to the diagnosis of myeloid leukemia cutis. Am J Clin Pathol 2009;132:101-10.

20. Kaddu S, Smolle J, Cerroni L, Kerl H. Prognostic evaluation of specific cutaneous infiltrates in B-chronic lymphocytic leukemia. J Cutan Pathol 1996;23:487-94. 